\title{
Keefektifan Counter Preassure Massage terhadap Intensitas Nyeri Kala I Fase Aktif Persalinan di Puskesmas Rawat Inap Langgam Kabupaten Pelalawan
}

\author{
Isrowiyatun Daiyah \\ Poltekkes Kemenkes Banjarmasin \\ ${ }^{*}$ corresponding author \\ Isrowiyatun Daiyah \\ JI.H.Mistar Cokrokusumo No.1A Banjarbaru Kalimantan Selatan \\ owizdaiyah1006@gmail.com
}

\begin{abstract}
Abstrak
Derajat nyeri dalam proses bersalin paling tinggi diantara nyeri yang lain. Nyeri hebat dapat menyebabkan kelahiran menjadi sulit. Penyulit persalinan salah satunya disebabkan oleh partus lama. Dari 36,35\% ibu mengalami komplikasi kebidanan di Puskesmas Rawat Inap Langgam dengan $14,1 \%$ disebabkan oleh partus lama. Teknik alami meredakan nyeri salah satunya dengan menawarkan counter preassure massage. Tujuan dari penelitian yakni menganalisis keefektifan counter preassure massage terhadap tingkatan nyeri kala I Fase aktif persalinan. Jenis penelitian ini adalah pre experimental design melalui rancangan one group pretest and posttest design dengan jumlah populasi 45 orang dan sampel 15 responden. Penelitian dilakukan di Puskesmas Rawat Inap Langgam pada Februari sampai Juni 2017. Analisa data menggunakan Dependent Samples T-test. Terdapat penurunan yang signifikan terhadap intensitas nyeri persalinan setelah perlakuan counter preassure massage $(p=0,000)$. Teknik counter preassure massage sangat berpengaruh menurunkan intensitas nyeri persalinan. Diharapkan kepada tenaga kesehatan agar dapat mengaplikasikan counter preassure massage sebagai salah satu pelayanan persalinan dalam mengurangi nyeri.
\end{abstract}

Kata kunci: Counter Preassure Massage; Intensitas; Nyeri Persalinan

\section{Impact of Counter Preassure Massage on Intensity of Pain in Active Phase of The First Stage Labor at Langgam Inpatient Health Center of Pelalawan District}

\begin{abstract}
The highest degree of pain in the process of childbirth among other pains. About $36.35 \%$ mothers experienced obstetric complications in Langgam Health Center with 14.1 being caused by prolonged labor. One of natural techniques to relieve labor pain to women in labor is by offering Counter Pressure Massage. This study aimed to analyze the impact of Counter Pressure Massage on the intensity of labor pain in active phase of the first stage of labor. This research was pre experimental with One Group Pretest and Posttest design. The population was 45 people and the sample was 15 people. The research was conducted at Langgam Inpatient Health Center in February-June 2017. Data analysis used dependent
\end{abstract}


Keefektifan Counter Preassure Massage terhadap Intensitas Nyeri Kala I Fase Aktif Persalinan di Puskesmas Rawat Inap Langgam Kabupaten Pelalawan

samples t-test. This study found that there was a significant decrease in the intensity of labor pain after the treatment of Counter Pressure Massage $(p=0.000)$. This study concluded that Counter Pressure Massage technique is very influential to reduce the intensity of labor pain. Health workers are expected to apply this massage as one of delivery services in reducing pain.

\section{Keyword: Counter Pressure Massage; Intensity; Labor Pain}

\section{Pendahuluan}

Proses persalinan yakni serangkaian proses diawali adanya kontraksi uterus yang mana terjadinya dilatasi secara terus menerus dari serviks, kelahiran bayi, dan kelahiran placenta hingga pemantauan 2 jam setelah placenta lahir (Rohani dkk, 2011). Proses persalinan melalui 4 kala, kala 1 terdiri dari 2 tahapan, yaitu tahapan laten dan tahapan aktif. Tahapan laten adalah tahapan masa awal persalinan sampai pembukaan mulai berjalan secara terus menerus yaitu pembukaan 1-3 cm. Tahapan aktif berawal dari kemajuan aktif dilatasi serviks sampai menjadi lengkap yaitu dari pembukaan 4-10 cm (Varney, 2007).

Proses yang panjang dari seluruh rangkaian tahapan persalinan terjadi pada Kala I. Pada primipara periode kala I fase aktif normalnya yaitu 12 jam dengan kemajuan pembukaan $1 \mathrm{~cm}$ setiap 1 jam dibandingkan multipara 8 jam dengan pertambahan pembukaan $2 \mathrm{~cm}$ setiap
1 jam (Asri \& Clervo, 2012). Hal ini disebabkan karena penipisan dan pembukaan serviks memerlukan waktu yang lebih lama (Nugroho, 2012).

Pada kala I terjadi kontraksi, penurunan terbawah janin, dan tekanan pada jalan lahir yang menyebabkan rasa nyeri pada ibu bersalin (Wiknjosastro, 2008). Diawali munculnya ketegangan yang kecil, kemudian terus meningkat sampai dengan lengkapnya pembukaan serviks dan siap untuk kelahiran janin dari rahim ibu, proses tersebut merupakan proses yang normal dan alamiah (Rohani dkk, 2011).

Nyeri menggambarkan kondisi terjadinya kerusakan jaringan tubuh (Potter \& Perry, 2005). Derajat nyeri dalam proses bersalin paling tinggi diantara nyeri yang lain, secara medis dikategorikan memiliki sifat kuat dan panas. Nyeri hebat dapat mengubah irama jantung dan menurukan aliran darah ke arteri koroner. Otot dasar perineum yang mengencang dapat 
Keefektifan Counter Preassure Massage terhadap Intensitas Nyeri Kala I Fase Aktif Persalinan di Puskesmas Rawat Inap Langgam Kabupaten Pelalawan

menyebabkan kelahiran menjadi sulit (Kennedy, 2013). Penyulit kala I adalah patus lama, gawat janin, dan ruptur uteri (Asri \& Clervo, 2012).

Nyeri memiliki sifat yang sangat subjektif karena setiap orang perasaan nyerinya berbeda dalam skala hal atau levelnya dan dialah yang dapat menjelaskan rasa nyeri yang dialaminya (Uliyah \& Hidayat, 2006). Faktor utama penyebab rasa nyeri pada proses bersalin yang sebenarnya merupakan hal normal dan tanpa rasa nyeri yang berarti adalah ketakutan, cemas dan tegang. Ketakutan mampu mempengaruhi keadaan his dan lancarnya pembukaan (Read dalam Rohani dkk, 2011). Rasa takut, cemas dan tegang selama proses persalinan dapat memicu hormon prostaglandin, katekolamin dan steroid yang dapat memicu stres (Potter \& Perry, 2005). Stres fisiologis memiliki efek fisik yang kuat yaitu terjadinya partus lama (Chapman, 2006)

\section{Berdasarkan hasil Survey} Penduduk Antar Sensus (SUPAS) Angka Kematian Ibu (AKI) berjumlah 305 per 100.000 kelahiran hidup pada tahun 2015. Indonesia termasuk salah satu yang memiliki AKI tertinggi di dunia. Penyebab langsung AKI adalah
$34 \%$ penyebab lain, $30,1 \%$ perdarahan, $26,9 \%$ hipertensi, 5,6\% infeksi, 1,8\% partus lama dan abortus 1,6\% (Kemenkes RI, 2015).

Peran bidan pada asuhan kala I adalah memberikan rasa nyaman yang merupakan keperluan dasar pada ibu saat bersalin. Tujuan asuhan kala I adalah untuk mempersiapkan proses keluarnya bayi semaksimal mungkin supaya kelahiran bayi berjalan secara fisiologis tanpa komplikasi, serta ibu dan bayi selamat dan sehat (Asri \& Clervo, 2012). Teknik alami meredakan nyeri dan kenyamanan bagi wanita bersalin salah satunya dengan menawarkan massage untuk kenyamanan emosi dan fisik ibu (Sinclair, 2009).

Teknik massage lazimnya ada dua yang diberikan dalam persalinan, yaitu teknik Back-Effleurage dan Counter Preassure yang kefektifannya relatif cukup dalam menurunkan nyeri pinggang tanpa menimbulkan efek samping (Danuatmaja \& Meiliasari, 2008).

National Birthday Trust melakukan studi terhadap 10.000 wanita didapatkan bahwa $90 \%$ wanita merasakan manfaat relaksasi dan massage guna mengurangi nyeri persalinan (Findley dan Chamberlain, 
Keefektifan Counter Preassure Massage terhadap Intensitas Nyeri Kala I Fase Aktif Persalinan di Puskesmas Rawat Inap Langgam Kabupaten Pelalawan

1999 dalam Schott dan Priest, 2008). Wanita yang diberikan massage selama persalinan mengalami penurunan kecemasan, nyeri yang berkurang, dan waktu persalinan lebih singkat secara bermakna (Field et al, 1997 dalam Schott dan Priest, 2008).

Pada penelitian yang dilakukan Sadat et.al di Amiral Momen Hospital Zabol Iran tahun 2008 mengatakan manual massage secara signifikan mengurangi nyeri dan waktu persalinan kala I fase aktif dengan $p$ value 0,0001. Sedangkan menurut Rejeki, dkk di Semarang pada tahun 2012 menyatakan dalam penelitiannya bahwa counter preassure massage lebih efektif mengurangi nyeri pinggang persalinan dari pada Back-Effleurage massage.

Berdasarkan data dari Dinas Kesehatan Kabupaten Pelalawan tahun 2016, persalinan oleh tenaga kesehatan dengan urutan 5 terbanyak yaitu pada wilayah kerja Puskesmas Rawat Inap Langgam, yakni sebanyak 631 persalinan dengan persentase $90,2 \%$. Dari jumlah tersebut terdapat $36,35 \%$ ibu mengalami komplikasi kebidanan, di mana jumlah tersebut melewati dari jumlah perkiraan ibu yang mengalami komplikasi kebidanan. Komplikasi tersebut disebabkan $14,1 \%$ partus lama, 10,6\% PEB, 6,4\% sebab lain dan $5,25 \%$ perdarahan (Dinkes Kabupaten Pelalawan, 2016).

\section{Metode}

Penelitian ini menggunakan design pre experimental design dengan one group pretest and posttest design, yaitu dengan cara melakukan pretest tingkatan nyeri persalinan kala I fase aktif kemudian diberikan intervensi pada subjek penelitian. Setelah itu dilakukan posttest atau pengukuran kembali pada subjek penelitian tersebut.

Penelitian ini populasinya yaitu seluruh ibu melahirkan pada kala I fase aktif di wilayah kerja Puskesmas Rawat Inap Langgam Kelurahan Langgam dengan ibu kala I fase aktif persalinan sebanyak 45 orang dari ibu yang melahirkan. Penelitian dilakukan di Puskesmas Rawat Inap Langgam pada Februari sampai Juni 2017

Sampel

penelitian mendapatkan terapi counter preassure massage dan dilakukan penilaian tingkatan nyeri persalinan sebelum dan setelah diberikan terapi counter preassure massage, kemudian setiap hasil penilaian akan dilakukan pengamatan atau 
Keefektifan Counter Preassure Massage terhadap Intensitas Nyeri Kala I Fase Aktif Persalinan di Puskesmas Rawat Inap Langgam Kabupaten Pelalawan

observasi. Jenis sampel yang diambil adalah nonprobability sampling.

Penelitian ini menggunakan sampel berjumlah 15 ibu bersalin yaitu mengambil sampel minimal untuk penelitian pre eksperimental (Sugiyono, 2011). Pengambilan sampel dengan metode purposive sampling serta kriteria inklusi yang dibuat peneliti.

Pengumpulan data dalam penelitian ini dilakukan dengan metode observasi secara langsung kepada ibu bersalin. Instrumen penelitian yang digunakan untuk mengetahui nyeri pada persalinan yakni skala penilaian numerik/ Numerical Rating Scale (NRS) dan prosedur counter preassure massage Peneliti mengolah data dan membuat analisa univariat dan bivariat yang dilakukan terhadap dua variabel, yaitu counter preasure massage sebagai variabel independennya, dan intensitas nyeri persalinan sebagai variabel dependennya. Analisa bivariate, diawali dengan uji normalitas, sebelum uji dependent sampel t-test.

\section{Hasil dan Pembahasan}

Tabel 1. Distribusi Frekuensi Berdasarkan Tingkatan Nyeri Saat Bersalin Sebelum Diberikan Counter Preassure Massage pada Ibu Kala I Fase Aktif Persalinan di Puskesmas Rawat Inap Langgam Kabupaten Pelalawan Tahun 2017

\begin{tabular}{lcc}
$\begin{array}{c}\text { Kategori Intensitas } \\
\text { Nyeri }\end{array}$ & $\begin{array}{c}\text { Jumlah } \\
(\mathrm{n})\end{array}$ & $\begin{array}{c}\text { Persentase } \\
(\%)\end{array}$ \\
\hline Tanpa Nyeri (0) & 0 & 0 \\
Nyeri Ringan (1-3) & 0 & 0 \\
Nyeri Sedang (4-6) & 6 & 40 \\
Nyeri Berat (7-10) & 9 & 60 \\
Jumlah & 15 & 100 \\
\hline
\end{tabular}

Sumber: Data primer tahun 2017

Tabel 1 menggambarkan tingkatan nyeri saat bersalin sebelum dilakukan counter preassure massage kepada ibu bersalin kala I fase aktif di Puskesmas Rawat Inap Langgam Kabupaten Pelalawan sebagian besar intensitas nyeri responden adalah nyeri berat dengan jumlah 9 responden $(60 \%)$.

Tabel 2. Distribusi Frekuensi Menurut Intensitas Nyeri Persalinan Setelah Diberikan Counter Preassure Massage pada lbu yang Bersalin Kala I Fase Aktif di Puskesmas Rawat Inap Langgam Kabupaten Pelalawan Tahun 2017

Kategori Tingkatan Jumlah Persentase

\begin{tabular}{ccc} 
Nyeri & $(\mathrm{n})$ & $(\%)$ \\
\hline Tanpa Nyeri (0) & 1 & 6,7 \\
Nyeri Ringan (1-3) & 14 & 93,3 \\
Nyeri Sedang (4-6) & 0 & 0 \\
Nyeri Berat (7-10) & 0 & 0 \\
Jumlah & 15 & 100 \\
\hline Sumber: Data primer tahun 2017 &
\end{tabular}

Sumber: Data primer tahun 2017

Tabel 2 menggambarkan intensitas nyeri persalinan setelah dilakukan counter preassure massage pada ibu kala I fase aktif persalinan di Puskesmas Rawat Inap Langgam Kabupaten Pelalawan sebagian besar intensitas nyeri responden adalah 
Keefektifan Counter Preassure Massage terhadap Intensitas Nyeri Kala I Fase Aktif Persalinan di Puskesmas Rawat Inap Langgam Kabupaten Pelalawan

nyeri ringan dengan jumlah 14 responden $(93,3 \%)$.

Tabel 3. Hasil Uji Normalitas Shapiro-Wilk Test

\begin{tabular}{lccc}
\hline & \multicolumn{3}{c}{ Shapiro-Wilk } \\
\cline { 2 - 4 } & statistik & $\mathrm{df}$ & Sig. \\
\hline Sebelum & .888 & 15 & .063 \\
Sesudah & .888 & 15 & .063
\end{tabular}

Sumber :Test of Normality Shapiro-Wilk SPSS 16

Dalam penelitian ini dilakukan

uji normalitas memakai uji Shapiro-
Wilk test (sampel < 50), pada 15 ibu melahirkan sebelum dan sesudah dilakukan counter preasure massage dan data berdistribusi normal, dengan signifikan $\quad 0,063 \quad(>0,05)$ sesuai dengan tabel 3.

Tabel 4. Perbedaan tingkatan Nyeri Persalinan Sebelum dan Setelah Dilakukan Counter Preassure Massage pada Ibu Kala I Fase Aktif yang Melahirkan di Puskesmas Rawat Inap Langgam Kabupaten Pelalawan Tahun 2017

\begin{tabular}{lccccccc}
\hline Perlakuan & $\mathrm{N}$ & Mean & Std. Deviasi & Min & Max & $\mathrm{t}$ & P-value \\
\hline Sebelum & 15 & 6,73 & 0,884 & 5 & 8 & & \\
Setelah & 15 & 1,73 & 0,884 & & & 15,448 & 0,000 \\
& & & & 0 & 3 & & \\
\hline
\end{tabular}

Dibuktikan dengan tabel 4 hasil perhitungan statistik standar deviasi sebesar 0,884 dan nilai rata-rata (mean) sebesar 1,73. Dari hasil uji didapatkan nilai $\mathrm{t}$ sebesar 15,448 dengan nilai $p$-value sebesar 0,000 . Didapati $p$-value $0,000<\alpha(0,05)$, membuktikan terdapat perbedaan yang berarti antara intensitas nyeri persalinan sebelum dan setelah diberikan counter preassure massage.

Hasil penelitian didapatkan bahwa intensitas nyeri sebagian besar responden sebelum dilakukan counter preassure massage adalah nyeri berat yaitu sebanyak 9 responden (60\%) dan setelah dilakukan counter preassure massage pada ibu bersalin kala I fase aktif intensitas nyeri responden sebagian besar adalah nyeri ringan yakni 14 responden $(93,3 \%)$.

Sebelum dilakukan counter preassure massage skala nyeri teringan (minimum) adalah 5 dan skala tertinggi adalah 8 , standar deviasi sebesar 0,884 dengan nilai rata-rata (mean) sebesar 6,73. Kemudian setelah diberikan counter preassure massage didapatkan skala nyeri teringan (minimum) adalah 0 dan skala nyeri tertinggi (maximum) yakni 3, standar deviasi sebesar 0,884 dengan nilai rata-rata (mean) 1,73.

Counter preassure massage efektif untuk menurunkan tngkatan nyeri saat kala I fase aktif persalinan. Ibu yang melahirkan pada kala I tahap 
Keefektifan Counter Preassure Massage terhadap Intensitas Nyeri Kala I Fase Aktif Persalinan di Puskesmas Rawat Inap Langgam Kabupaten Pelalawan

aktif dengan tingkat nyeri sedang dan berat menurut peneliti adanya beberapa faktor penyebab antara lain faktor usia, paritas, dan pengalaman masa lalu. Teori lain mengatakan variabel penting yang mempengaruhi nyeri yaitu usia, terkhusus pada anakanak dan orang dewasa. Ditemukan adanya perbedaan dan perkembangan diantara kelompok usia ini dan mampu memberi pengaruh bagaimana seseorang bereaksi terhadap nyeri (Andarmoyo, 2013).

Teori tentang pada usia berapa nyeri mempunyai ambang yang rendah belum diketahui dengan pasti, namun umumnya teori menyatakan bahwa usia memberi pengaruh pemahaman seseorang terhadap nyeri yang dirasakan. Menurut Yuliatun (2008) otak mengalami degenerasi sejalan bertambahnya umur seseorang sehingga orang yang lebih tua memiliki ambang nyeri lebih rendah dan mengalami pengurangan sensasi nyeri lebih banyak.

Paritas juga mempengaruhi tingkatan rasa nyeri ibu saat kala I fase aktif proses persalinan karena setiap individu belajar dari riwayat merasakan nyeri. Ibu multipara akan lebih mudah untuk menjelaskan sensasi nyeri persalinan dibandingkan dengan ibu yang mengalami nyeri persalinan pada kelahiran anak pertama (Andarmoyo, 2013).

Perbedaan nyeri persalinan primipara dan multipara bisa dikarenakan perbedaan mekanisme pembukaan serviks yakni, pada primipara yang terlebih dahulu membuka adalah ostium uteri internum kemudian menipis, mendatar sedangkan multipara sudah ada pembukaan sedikit pada ostium uteri internum dan eksternum, proses penipisan dan pendataran serviks terjadi bersamaan, maka kecenderungan nyeri pada primipara lebih berat dibandingkan pada multipara (Wiknjosastro, 2002).

Counter preassure massage dapat menghentikan gerbang/gate rasa nyeri. Gate control theory menjelaskan bahwa dalam proses melahirkan implus nyeri bergerak dari uterus sepanjang serat-serat syaraf besar ke subtansia gelatinosa di dalam spina kolumna, sel-sel transmisi memberikan refleksi ke otak terhadap perintah nyeri, adanya stimulasi (seperti vibrasi atau massage) menyebabkan perintah yang berlawanan lebih cepat, kuat dan 
Keefektifan Counter Preassure Massage terhadap Intensitas Nyeri Kala I Fase Aktif Persalinan di Puskesmas Rawat Inap Langgam Kabupaten Pelalawan

menyebar sepanjang serat syaraf kecil.

Counter preassure massage merupakan teknik massase yang mempunyai kontribusi besar dalam menurunkan atau mengurangi nyeri saat proses bersalin kala I fase aktif. Hasil penelitian ini sependapat dengan hasil penelitian oleh Sadat et.al di A miral Momen Hospital Zabol Iran tahun 2008 secara signifikan dengan $p$ value 0,0001 manual massage dapat mengurangi nyeri dan durasi proses kala I fase aktif persalinan.

Hasil penelitian lain yang mendukung yakni penelitian yang dilakukan Rejeki dkk tentang tingkat nyeri dan kadar prostaglandin-E2 ibu inpartu kala I dengan intervensi counter preassure massage di RSU Dr Karyadi Semarang tahun 2014. Penelitian ini mengatakan metode counter preassure massage sangat signifikan menurunkan tingkat nyeri persalinan dengan $p$ value sebesar 0,000 .

Beberapa penelitian yang
membandingkan efektifitas teknik
counter preassure massage dengan
teknik lainnya terdapat dalam
penelitian yang dilakukan oleh Rejeki
dkk tentang tingkat nyeri pinggang

kala I persalinan dengan teknik backeffleurage dan counter preassure massage di RSUD Ambarawa Kabupaten Semarang tahun 2012 menunjukkan bahwa teknik counter preassure massage lebih efektif mengurangi nyeri pinggang persalinan.

\section{Simpulan}

Counter preassure massage merupakan teknik relaksasi nonfarmakologi yang efektif mengurangi nyeri kala I fase aktif persalinan. Teknik counter preassure massage dapat disosialisasikan dan diaplikasikan oleh bidan-bidan dalam memenuhi kebutuhan kala I tahap aktif persalinan dan membuat ibu -ibu dalam proses bersalin mampu beradaptasi terhadap nyeri yang dialaminya saat persalinan.

\section{Daftar Pustaka}

Andarmoyo, Sulistyo. (2013). Konsep dan Perasat Keperawatan Nyeri. Yogyakarta: Ar-Ruzz Media.

Asri, D, H. Clervo Cristine, P. (2012). Asuhan Persalinan Normal.Yogyakarta: Nuha Medika.

Chapman, Vicky. (2006). Asuhan Kebidanan Persalinan dan Kelahiran. Jakarta: EGC.

Danuatmaja, Benny \& Meiliasari, Mila. (2008). Persalinan Normal 
Keefektifan Counter Preassure Massage terhadap Intensitas Nyeri Kala I Fase Aktif Persalinan di Puskesmas Rawat Inap Langgam Kabupaten Pelalawan

Tanpa Rasa Sakit. Jakarta: Puspa Swaka.

Dinas Kesehatan Kabupaten Pelalawan. (2016). Profil Kesehatan Kabupaten Pelalawan. Kerinci: Dinkes Kab. Pelalawan.

Kennedy, Betsy. B. (2013). Modul Manajemen Intrapartum. Jakarta: EGC

Kementerian Kesehatan Republik Indonesia. (2015). Profil Kesehatan Indonesia. http//www.kemkes.go.id.

Diakses tanggal 24 Februari 2017.

Nugroho, Taufan. (2012). Patologi Kebidanan. Yogyakarta: Nuha Medika.

Notoatmodjo, Soekidjo. (2012). Metodologi Penelitian Kesehatan. Jakarta: Rineka Cipta.

Potter, Patricia \& Perry, Grifin Anne. (2005). Buku Ajar Fundamental Keperawatan: Konsep, Proses, dan Praktik Edisi 4. Jakarta: EGC.

Rejeki, Sri dkk. (2012). Tingkat Nyeri Pinggang Kala I Persalinan Melalui Tekhnik Back-Effluerage dan Counter Preassure di RSUD Ambarawa Kabupaten Semarang. Jurnal Keperawatan Maternitas Vol. 1 No. 2. http://download.portalgaruda.org . Diakses tanggal 24 Februari 2017.

Rohani, dkk. (2011). Asuhan Kebidanan pada Masa Persalinan. Jakarta: Salemba Medika.

Schott, Judith \& Priest Judy. (2008). Kelas Antenatal. Jakarta: EGC

Sinclair, Constance. 2009. Buku Saku
Kebidanan. Jakarta: EGC.

Sadat Hasheni Zohreh et al. (2008). The Impact of Manual Massage on Intensity and Duration of Pain at First Phase of Labor in Primigravid Women. International Journal of Medicine Research Vol.1 Issue.4 Page No.16-18. http://www.medicinesjournal.co $\mathrm{m}$. Diakses tanggal 24 Februari 2017.

Sugiyono. (2011). Statistika untuk Penelitian. Bandung: CV. Alfabeta.

Varney, H. (2007). Buku Ajar Asuhan Kebidanan Edisi 4. Jakarta: EGC 